\title{
MOTIVATION IN SOCIAL SCIENCE LEARNING IN DIGITAL ERA: CASE STUDY OF MULTIMEDIA USE
}

\author{
Nur Fadhilah, Dhea Adela \\ Universitas Sebelas Maret \\ nurfadhilah795@gmail.com
}

\section{Article History}

accepted 09/07/2018

approved 01/08/2018

published 17/09/2018

\section{Keywords}

IPS; motivasi; multimedia; sekolah dasar

\begin{abstract}
Pembelajaran IPS dilakukan untuk membentuk metal siswa agar siap dalam menghadapi lingkungan sosialnya, khusunya di era digita yang saat ini sangat pesat. Era dimana manusia secara umum memiliki gaya hidup baru yang tidak bisa dilepaskan dari perangkat yang serba elektronik. Artikel ini bertujuan untuk mendeskripsikan proses pembelajaran IPS menggunakan multimedia pada era digital pada tiga SD di Kecamatan Kebumen. Pembelajaran yang dirasa membosankan bagi siswa ini memerlukan sebuah inovasi guna tercapainya sebuah kompetensi IPS. Penggunaan media pada pembelajaran dapat menjadi salah satu alternatifnya. Media yang digunakan adalah multimedia, yang berarti dalam sebuah pembelajaran, menggunakan beberapa media yang berbeda-beda. Penelitian ini merupakan penelitian kualitatif dengan Teknik pengumpulan data wawancara semi terstruktur, observasi partisipasi pasif dan didukung oleh dokumen yang terkait. Secara ringkas, respon siswa terhadap pembelajaran menggunakan multimedia dapat menumbuhkan motivasi siswa dalam mencapai sebuah kompetensi.
\end{abstract}

Social, Humanities, and Education Studies (SHEs): Conference Series https://jurnal.uns.ac.id/shes
p-ISSN 2620-9284

e-ISSN 2620-9292 


\section{PENDAHULUAN}

Era digital adalah kehidupan dimana manusia menggunakan teknologi dalam sebagian besar pemenuhan kebutuhannya. Era digital terlahir dengan kemunculan digital, jaringan internet khususnya teknologi informasi komputer (Setiawan, 2017). Media baru era digital memiliki karakteristik dapat dimanipulasi, bersifat jaringan atau internet. Meluasnya teknologi ini juga mempengaruhi pembelajaran di setiap jenjang, termasuk sekolah dasar.

Pembelajaran IPS bertujuan untuk mengembangkan potensi siswa agar peka terhadap masalah sosial yang terjadi di masyarakat, memiliki sikap mental positif terhadap perbaikan segala ketimpangan yang terjadi, dan terampil mengatasi setiap masalah yang terjadi sehari-hari (Trianto, 2011: 176). Hal ini senada dengan pendapat Martorella (1994:7) yang menyatakan bahwa: "The Social Studies are selected information and modes of investigation from the social sciences, selected information from any area that relates directly to an undestanding of individuals, groups, and societies and applications of the selected information to citizenship education". Pembelajaran sosial adalah informasi yang dipilih dan mode penyelidikan dari ilmu sosial, informasi yang dipilih dari setiap area yang berhubungan langsung dengan pemahaman individu, kelompok, dan masyarakat dan aplikasi dari informasi yang dipilih untuk pendidikan warganya. Pendapat ini diperkuat oleh Jarolimek (1986: 4) yang menyatakan bahwa "The major mission of social studies education is to help children learn about the social world in which they live and how it got that way; to learn to cope with social realities; and to develop the knowledge, attitudes, and skilsl, needed to help shape an enlightened humanity. Misi utama pendidikan ilmu sosial adalah untuk membantu anak-anak belajar tentang dunia sosial tempat mereka tinggal dan bagaimana hal itu terjadi; belajar untuk mengatasi realitas sosial; dan untuk mengembangkan pengetahuan, sikap, dan keterampilan, diperlukan untuk membantu membentuk kemanusiaan yang tercerahkan.

Upaya yang dapat dilakukan oleh seorang guru guna mecapai tujuan tersebut

adalah mengemas pembelajaran yang menarik dan bermakna agar materi tersampaikan dengan baik sekaligus memotivasi siswa dalam mengikuti pembelajaran dikelas dengan harapan nantinyasiswa dapat mencapai sebuah kompetensi tertentu dengan optimal. Pengemasan pembelajaran tersebut disesuaikan dengan karakter IPS yang berisi materi konsep, nilai-nilai sosial, kemandirian dan kerja sama (Susanto, 2014: 22), dan sisesuaikan dengan era digital. Karakteristik tersebut menunjukkan bahwa pembelajaran IPS termasuk pembelajaran yang abstrak. Konsep- konsep seperti waktu, perubahan, kesinambungan (continuity), arah mata angin, lingkungan, ritual, akulturasi, kekuasaan, demokrasi, nilai, peranan, permintaan, atau kelangkaan adalah konsep- konsep abstrak dalam program studi IPS harus dibelajarkan kepada siswa SD (Purnamasari, 2011:16). Maka dari itu, kepiawaian guru dalam mengemas pembelajaran sangat diperlukan untuk menyampaikan materi-materi abstrak tersebut kepada siswa kelas IV yang notabennya masuk pada tahap operasional konkret (Sobur, 2011:132). Operasi konkret merupakan kegiatan mental yang difokuskan pada objek dan peristiwa nyata yang dapat diukur (Desmita, 2013:156). Diukur dalam hal ini diselidiki dengan mencoba dan mengekplorasi objek atau peristiwa secara logis yang didorong oleh rasa ingin tahu siswa(Sobur, 2011:132). Erikson berpendapat bahwa anak kelas IV SD mempunyai karakteristik senang berkelompok dan berorganisasi, rajin mengerjakan tugas, dan perlu pengarahan dari orang tua (Sobur, 2011: 136), karena tanpa pengarahan dari orang tua, anak akan menggunakan teknologi tidak sebagaimana mestinya. Karakteristik siswa yang menunjukkan cara berpikir secara logis dan abstrak yang didorong rasa ingin tahu yang tinggi merupakan salah satu faktor penentu seorang guru dalam mengemas pembelajaran, khususnya dalam hal ini pembelajaran IPS. 
Pembelajaran mengandung arti setiap kegiatan yang dirancang untuk membantu seseorang mempelajari suatu kemampuan dan nilai yang baru. Corey mengemukakan bahwa pembelajaran merupakan suatu proses dimana lingkungan seseorang secara disengaja dikelola untuk memungkinkan ia turut serta dalam tingkah laku tertentu dalam kondisi-kondisi khusus atau menghasilkan respon terhadap situasi tertentu (Sagala, 2014:61). Hamalik (2012:57) mengemukakan, pembelajaran adalah suatu kombinasi yang tersusun meliputi unsur-unsur manusiawi, material, fasilitas, perlengkapan, dan prosedur yang saling mempengaruhi guna mencapai tujuan pembelajaran. Pembelajaran pada artikel ini dikhususkan pada pembelajaran IPS. Pembelajaran IPS di sekolah dasar memberikan pengetahuan dasar dan keterampilan sebagai warga negara sedini mungkin, yaitu keterampilan berpikir kritis, sikap dan kecakapan-kecakapan dasar siswa yang berpijak pada kenyataab kehidupan sosial kemasyarakatan sehari-hari dan memenuhi kebutuhan bagi kehidupan sosial siswa di masyarakat (Susanto, 2013: 138). Dari pendapat tersebut, terlihat beberapa ruang lingkup IPS di dalamnya. Ruang lingkup IPS menurut Permendiknas Nomor 22 Tahun 2006 (Nawardi \& Naga, 2014: 11) adalah sebagai berikut: (a) sistem sosial dan budaya; (b) manusia, tempat, dan lingkungan; (c) perilaku ekonomi dan kesejahteraan; (d) waktu, keberlanjutan, dan perubahan. Pada artikel ini akan membahas materi IPS tentang manusia, tempat dan lingkungan serta perilaku ekonomi dan kesejahteraan.

Melihat dari karakter siswa, lingkup pembelajaran IPS dan maraknya teknologi informasi saat ini, dapat dijadikan acuan bagi guru dalam penyajian pembelajaran IPS dan penentuan strategi serta media pembelajaran yang sesuai guna meningkatkan motivasi belajar siswa. Motivasi yang berkualitas bagus dapat ditingkatkan dengan menciptakan iklim pengajaran yang memiliki karakteristik dukungan tinggi terhadap otonomi, struktur, dan keterlibatan siswa yang dapat menjadi kontribusi dalam proses kepuasan kebutuhan (Vansteenkiste et al.2009). Cheang (2009) pun berpendapat bahwa pendekatan pembelajaran yang berpusat pada siswa (learner-centered approach) efektif dalam meningkatkan beberapa domain motivasi dan strategi pembelajaran. Jadi, salah satu cara guru untuk meningkatkan motivasi siswa dalam pembelajaran adalah menerapkan pendekatan yang berpusat pada siswa. Pendekatan tersebut menekankan pada minat, kebutuhan dan kemampuan individu, menjanjikan model belajar yang menggali motivasi intrinsik untuk membangun masyarakat yang suka dan selalu belajar (Trinova, 2013). Lebih lanjut, menurut Trinova, salah satu tahap pendekatan berpusat pada siswa adalah penggunaan beberapa media yang mengonkretkan hal-hal abstrak bagi siswa. Salah satunya adalah multimedia.

Smaldino mengemukakan istilah multimedia berkaitan dengan digunakannya beberapa bentuk/jenis media secara sistematis maupaun serentak dalam menyampaikan suatu informasi (Anitah, 2008: 60). Nachimuthu (2012:167) berpendapat bahwa multimedia berarti kombinasi teks, audio, gambar diam, animasi, video dan konten interaktivitasyang disampaikan secara elektronik. Beberapa penelitian di bidang-bidang tertentu telah menghasilkan produk yang mendukung pembelajaran seperti video (Borko \& Pitman, 2008); pembelajaran video dengan bantuan komputer (Vijayakumari, 2009); efek emosional yang kuat (Moreno \& Mayer, 2004) dan penggunaan klip yang jelas (Kobre, 2012).

Fakta di lapangan, dua guru kelas telah menggunakan media dalam pembelajaran, namun hanya terpaku satu media saja dan belum menggunakan media berbasi digital. Khususnya pada pembelajaran IPS, apabila terdapat beberapa materi yang membutuhkan media gambar, guru hanya bergantung pada gambar yang ada pada buku paket belajar. Satu guru kelas lagi tidak menggunakan media karena kurangnya sarana dan prasarana. Hal ini jelas menyebabkan siswa kurang termotivasi dalam belajar yang nantinya berimbas pada kurang tercapainya sebuah kompetensi 
pembeajaran. Upaya yang dapat dilakukan untuk memotivasi siswa dalam belajar adalah penggunaan multimedia berbasis teknologi di era sekarang dalam pembelajaran IPS.

\section{METODE}

Penelitian ini menggunakan pendekatan kualitatif studi kasus di tiga SD di Kecamatan Kebumen yang memiliki persamaan karakter, yakni terakreditasi A dan menggunakan kurikulum 2006. Tiga sekolah tersebut mewakili tiga gugus di Kecamatan Kebumen bagian timur. Narasumber pada penelitian ini adalah kepala sekolah di tiap SD selaku pengawas pembelajaran di sekolah, guru kelas IV di tiap SD selaku pemegang wewenang tertinggi pada kelas tersebut dan mengetahui karakter setiap siswa di tiap kelas mereka, dan siswa kelas IV pada tiga SD tersebut yang berjumlah 89 siswa, 43 laki-laki dan 46 perempuan. Teknik pegumpulan data pada penelitin ini adalah wawancara semi terstruktur kepada kepala sekolah dan guru pada tiap SD serta beberapa siswa kelas IV. Wawancara kepada kepala sekolah guna menggali informasi tentang ketersdiaan media pembelajaran di sekolah dan proses mengajar guru kelas. Wawancara kepada guru kelas guna menggali informasi tentang penggunaan media dalam pembelajaran, proses pembelajaran yang dilakukan, serta respon siswa terhadap pembelajaran dengan dan tanpa penggunaan media. Sampel siswa kelas IV yang representatif pada tiap SD guna menggali informasi tentang respon mereka terhadap pembelajaran dengan dan tanpa menggunakan media. Teknik pengumpulan data yang kedua adalah observasi patisipasi pasif pada guru dan siswa pada tiap SD, yakni peneliti mengamati langsung proses pembelajaran di kelas namun tidak turut campur dalam kegiatan pembelajaran, serta didukung dengan analisis dokumen yang berupa silabus, RPP, LKS, buku sumber materi belajar siswa dan media pembelajaran yang digunakan. Validitas data pada penelitian ini menggunakan triangulasi sumber dan triangulasi teknik. Analisis data pada penelitian ini berlangsung selama proses pengumpulan data dan setelah selesai pengumpulan data yang menggunakan teknik dari Miles and Huberman mulai dari aktivitas data reduction, data display, dan conclusion drawing/verivication(Sugiyono, 2017: 337).

\section{HASIL DAN PEMBAHASAN}

Hasil wawancara dengan guru SD pertama menunjukkan bahwa belum menggunakan media pada pembelajaran IPS, apabila terdapat beberapa materi yang membutuhkan media, hanya sebatas menggunakan gambar yang ada pada buku materi. Hal itu pula diakui oleh siswa, bahwa pada pembelajaran IPS guru lebih sering bercerita tentang materi. Hal itu didukung oleh observasi yang telah dilakukan bahwa tidak sedikit siswa yang mengantuk, namun tetap mengikuti pembelajaran. Belum menggunakannya media dalam pembelajaran ini tidak sesuai dengan pendapat Hidayati (2012) yang mengemukakan bahwa proses pembelajaran yang berdasarkan kurikulum memerlukan dukungan dari media pembelajaran. Hal ini sesuai dengan fungsi media menurut Sadiman dkk (2014) bahwa dengan menggunakan media dalam pembelajaran dapat memperjelas penyampaian informasi agar tidak terlalu bersifat umum.

Hasil observasi pada SD kedua menunjukkan bahwa guru kelas telah menggunakan power point sebagai media dalam menyampaikan pembelajaran. Hal ini didukung hasil wawancara kepala SD tersebut bahwa sekolah menyediakan LCD proyektor untuk mendukung program pembelajaran dengan total 5 LCD proyektor yang masih layak untuk digunakan. Guru kelas mengakui, penggunaan media dalam pembelajaran sosial ini memudahkannya untuk mendatangkan kehidupan sosial sebenarnya di kelas. Sehingga siswa dapat dikondisikan dalam pembelajaran karena merasa senang dengan pembelajaran menggunakan LCD. Hal ini sesuai dengan pendapat Oroujulu (2012) yang mengemukakan bahwa media merupaka institusi sosial 
yang meruapak penyampai informasi penting mengenai budaya, politik dan kehidupan sosial. Hal itu membantu guru menggambarkan hal yang abstrak mejadi konkret bagi siswa.

SD ketiga telah memiliki LCD sebagai media, namun guru kelas mengakui bahwa belum menggunakan alat tersebut secara optimal sebagai media. LCD proyektor tersebut digunakan untuk hanya menampilkan gambar yang ada di buku sumber materi, namun karena daya listrik sekolah tersebut kurang mencukupi jadi guru lebih memilih untuk jarang menggunakan LCD proyektor. Beberapa siswa mengakui lebih senang apabila pembelajaran IPS menggunakan media LCD, karena dengan LCD mereka tidak perlu membaca semua materi dalam buku. Kepala SD mengemukakan dalam wawancara, bahwa daya listrik sebenarnya mampu untuk menopang LCD, namun terbatas hanya untuk satu LCD. Hal itu menjadi salah satu faktor guru untuk lebih memilih untuk tidak menggunakan LCD. Fakta tersebut menunjukkan bahwa kendala dalam pemanfaatan media adalah kurannya sarana prasarananya itu sendiri. Sesuai dengan pendapat Asis (2015) bahwa kendala pemanfaatan media adalah kurangnya ketersediaan LCD proyektor dan daya listrik yang memadai. Berdasarkan kedala ini, sebaiknya dapat menjadi acuan kepala sekolah untuk lebih menyediakan sarana prasarana dalam pembelajaran.

Hasil penelitian awal dari ketiga SD dapat diringkas dalam tabel 1 tentang proses pembelajaran yang dilakukan guru dan respon siswa terhadapnya.

Tebel 1. Proses Pembelajaran Guru dan Respon Siswa sebelum menerapkan Multimedia

\begin{tabular}{|c|l|l|}
\hline Sekolah Dasar & \multicolumn{1}{|c|}{ Guru } & \multicolumn{1}{c|}{ siswa } \\
\hline 1 & $\begin{array}{l}\text { Hanya menggunakan gambar di } \\
\text { buku sumber materi }\end{array}$ & Mengantuk dan bosan \\
\hline 2 & Menggunakan power point & $\begin{array}{l}\text { Merasa senang dan lebih } \\
\text { kondusif dalam belajar }\end{array}$ \\
\hline 3 & $\begin{array}{l}\text { Sesekali menggunakan LCD } \\
\text { untuk menampilkan gambar yang } \\
\text { sama dengan buku sumber materi }\end{array}$ & $\begin{array}{l}\text { Lebih tertarik dengan } \\
\text { penggunaan LCD dalam } \\
\text { belajar }\end{array}$ \\
\hline
\end{tabular}

Tabel 1 dapat kita kaji bahwa dalam pembelajaran di SD terdapat dua SD yang belum menjadikan karakteristik siswa sebagai dasar perlunya penggunaan media untuk mengurangi hal-hal yang abstrak bagi siswa karena menurut Desmita (2013:156) siswa SD kelas IV memfokuskan segala objek dan peristiwa pada hal yang nyata dan dapat diukur. Maka dari itu, guru sebaiknya menggunakan media dalam pembelajaran yang sesuai dengan usia siswa, karena menurut Mares, Sivakumar, \& Stephenson, (2015), media yang baik dalah media yang sesuai dengan usia siswa.

Pertemuan berikutnya, peneliti menyarankan ketiga guru SD untuk menggunakan beberapa media dalam menyampaikan pembelajaran IPS. Dengan menggunakan media, pembelajaran akan berjalan dengan efektif (Hidayati, 2012). Media yang digunakan dalam pembelajaran IPS pada tiga SD adalah video, audio, gambar, dan flashcard. Beberapa media tersebut digunakan dalam satu waktu. Tidak keempatnya sekaligus, namun lebih dari satu dari keempat media tersebut digunakan secara bersamaan.

SD pertama menggunakan video dan flashcard dalam pembelajarannya. Kedua media yang digunakan tersebut sesuai dengan kompetensi yang akan dicapai siswa, beratri dalam pemilihan media guru telah memperhatikan karakter media dan karakter siswa itu sendiri. Hal ini sesuai dengan pendapat Kirkorian \& Anderson (2008), selain memperhatikan karakter media pembelajaran, juga memperhatikan karakter seperti demografi, usia, dan jenis kelamin siswa. Video yang digunakan menunjukkan 
sebuah cerita masalah sosial dengan animasi sesuai dengan siswa. Hasil observasi menunjuukan respon siswa tampak antusias dalam memperhatikan pembelajaran, tidak ada yang meletakkan kepala mereka di meja seperti pada awal penelitian karena mengantuk. Pemutaran video dilakukan sebanyak dua kali. Pemutaran pertama siswa ditugaskan untuk memperhatikan video saja, sedangkan pda pemutaran kedua siswa mecatat hal penting sesuai degan LKS yang dibagikan guru dan terkait dengan video. Flashcard digunakan guru sebagai media kuis dalam pembelajaran. Satu sisi flashcrad berisi tentang gambar sebuah permasalahan sosial, sedangkan pada sisi yang lain dibiarkan kosong. Siswa secara berpasangan ditugaskan untuk menganalisis sebab dan cara untuk menanggulangi gambar yang mereka peroleh sesuai pembelajaran yang telah mereka dapatkan di awal, dan menuliskannya pada sisi flashcard yang kosong. Dari hasil observasi, tiap pasang siswa berusaha mengerjakan tugas tersebut. Tampak kelas menjadi riuh karena proses diskusi dari tiap pasang siswa. Fakta itu menunjukkan bahwa penggunaan dua media dalam pembelajaran akan meningkatkan motivasi belajar siswa. Sesuai dengan pendapat Shah \& Khan (2015) bahwa penggunaan multimedia dalam pembelajaran dapat meningkatkan motivasi dan prestasi akademik siswa.

Hasil wawancara mengenai terdapat beberapa kendala yang ditemui guru dalam mmenyusun atau membuat media yakni membutuhkan dana pribadi dan waktu yang lebih. Sementara tugas guru tidak hanya sekedar membuat media, namun banyak administrasi lain yang harus dikerjakan. Hal itu menyebabkan guru lebih memilih menggunakan media video yang diunduh dari aplikasi youtube. Sesuai dengan pendapat Moghavvemi (2018), yutube merupakan media efektif dalam meningkatkan pengalaman belajar jika video tersebut memang relevan dengan subjek pembelajaran.

SD kedua, karena telah memiliki sarana prasarana yang memadai, lebih memilih untuk menampilkan video, gambar, dan teks menggunakan LCD dan proyektor. Sama dengan SD pertama, video yang dipilih guru merupakan video yang diunduh dari youtube, yang dirasa lebih praktis daripada membuatnya sendiri. Youtube merupakan aplikasi teratas ketiga yang sering diakses oleh warga dunia (Alexa, 2015). Pemutaran video dilakukan untuk menarik perhatian siswa agar fokus pada pembelajaran. Pada saat pemutaran, yang hanya berlangsung sekali, siswa hanya ditugaskan untuk memperhatkan video tanpa ada kegiatan yang lain. Video tersebut berisi tentang masalah sosial yang ada di kehidupan sekitar, mulai dari penyebabnya dan solusi yang digunakan untuk menanggulangi. Media gambar tentang masalah sosial, digunakan guru sebagai bahan siswa berdiskusi secara berpasangan, guna mengkroscek apa yang telah siswa dapatkan dari pemutaran video. Tiap pasang siswa mendapat kesempatan menyampaikan hasil analisisnya tentang penyebab dan solusi dari masalah sosial yang ditampilkan secara lisan. Hal ini dapat melatih keterampilan berbicara dan berkomunikasi siswa di depan kelas. Kemampuan berkomunikasi dengan baik, sangat berguna untuk kepuasan pribadi, prestasi akademik, dan kesuksesan karir belajar (Morreale \& Pearson, 2008). Pada konteks sekolah,pembicara yang baik mampu menyampaikan kemampuan, ide, dan pendapatnya. Kedepannya, malu berkomunikasi dengan baik akan meningkatkan hubungan dengan teman sebaya, orang tua dan guru(Hunt, Wright, \& Simonds, 2014). Media teks, berisi tentang kata kunci sebab dan solusi masalah sosial, ditampilkan di akhir kuis, guna menyamakan persepsi antar guru dan siswa. Ketiga media tersebut semua menggunakan media non cetak, yakni LCD proyektor.

Tampak dari hasil observasi pada SD kedua, siswa kondusif dalam pembelajaran. Tidak ada siswa yang membuat kegaduhan selama pembelajaran. Semua siswa berusaha untuk menjawab kuis berdasarkan gambar yang ditampilkan guru. Hasil wawancara menunjukkan siswa merasa senang dan lebih mudah menerima pembelajaran apabila pembelajaran menggunakan media. Hal ini menunjukkan bahwa motivasi tehadap pembelajaran meningkat yang dibuktikan dari 
hasil belajar siswa yang mempunyai nilai rata-rata kelas di atas kriteria minima I(75), dari 74 menjadi 79.

SD ketiga menggunakan media video dan audio. Sama dengan video pada kedua SD di atas, guru memilih youtube sebagai aplikasi pencari video dalam pembelajaran. Dengan melihat video, dapat meningkatkan komunikasi antara guru dan siswa (Torres-Ramírez et al., 2014). hal itu dapat dibuktikan dari pemberian pertanyaan dari guru untuk siswa secara individu guna mengkroscek pembelajaran apa yang telah didapat dari pemutaran video. Guru juga menyelenggarakan siswa untuk berpendapat, apabila pendapatnya berbeda dengan yang lain. Hasil wawancara dengan siswa menunjukkan bahwa siswa merasa tertarik karena dirasa seperti menonton film dalam kelas, apabila pembelajaran menggunakan video. Selain pertanyaan-pertanyaan dari guru untuk mengkroscek pemahaman siswa, guru juga menggunakan media audio yang berisi penyiaran berita tentang masalah sosial. Siswa dengan seksama mendengarkan audio yang diputarkan melalui handphone guru, kemudian siswa menuliskan sebab dan solusi dari maslaah sosial tersebut secara berkelompok. Strategi ini membantu siswa dalam memperhatikan sesuatu dengan efektif (Kutlu, 2009). Dari hasil observasi juga menunjukkan bahwa siswa termotivasi dalam belajar karena siswa semangat meminta untuk diputarkan kembali video yang telah ditayangkan. Bukan hanya sekedar untuk menikmati video yang diputar, namun siswa juga mudah memahami materi yang diterimanya, terbukti dari durasi diskusi siswa yang tidak terlalu lama dalam menjawab kuis.

Fakta dari tiga SD di atas dapat kita ringkas dalam tabel 2 dibawah ini.

Tebel 2. Proses Pembelajaran Guru dan Respon Siswa setelah Menerapkan Multimedia

\begin{tabular}{|c|l|l|}
\hline Sekolah Dasar & \multicolumn{1}{|c|}{ Guru } & \multicolumn{1}{|c|}{ siswa } \\
\hline 1 & $\begin{array}{l}\text { Menggunakan video youtube } \\
\text { (LCD proyektor) dan flascard. }\end{array}$ & Riuh diskusi materi \\
\hline 2 & $\begin{array}{l}\text { Menggunakan media video } \\
\text { youtube, gambar dan teks (LCD } \\
\text { proyektor) }\end{array}$ & $\begin{array}{l}\text { Rata-rata kelas diatas kriteria } \\
\text { minimal }\end{array}$ \\
\hline 3 & $\begin{array}{l}\text { Menggunaka media video } \\
\text { youtube(dari LCD proyektor) dan } \\
\text { audio (dari handphone) }\end{array}$ & $\begin{array}{l}\text { Durasi menjawab kuis yang } \\
\text { tida terlalu lama }\end{array}$ \\
\hline
\end{tabular}

Tabel 2 dapat kita kaji dan kita bandingkan dengan tabel 1, tampak terdapat perubahan respon siswa dalam pembelajaran dari sebelum menerapkan multimedia hingga setelah menerapkan multinedia. Dari beberapa fakta tersebut dapat kita simpulkan, di era digital ini, multimedia berbasis teknologi dapat memotivasi siswa dalam belajar.

\section{KESIMPULAN}

Era digital telah membawa berbagai perubahan yang baik sebagai dampak positif bagi yang bisa ,menggunakanya sebaik mungkin, khususnya dalam pembelajaran. Pembelajaran saat ini sebaiknya menyesuaikan dengan era saat ini yang serba teknologi untuk meningkatkan motivasi siswa, seperti menggunakan multimedia dalam pembelajaran. Multimedia yang dapat digunakan adalah video, audio, gambar, dan teks yang ditampilkan menggunakan teknologi saat ini seperti LCD proyektor dan handphone. Dalam penyususnan media, terlebih dahulu guru mempertimbangkan karakter siswa dan karakter materi IPS sebagai acuannya. Kendala yang dihadapi pada saat penyusunan media adalah kurangnya waktu guru, jarena banyaknya tugas administrasi yang harus dipenuhi guru. 


\section{DAFTAR PUSTAKA}

Alexa (2015). Statistic report: Top sites in Spain. Diunduh dari http://www.alexa.com/ topsites/countries/ES pada tanggal 6 Mei 2018.

Anitah, S. (2008). Media Pembelajaran. Surakarta: UNS press.

Asis, S. (2015). Pemanfaatan Media Pembelajaran Berbasis Multimedia dalam Pembelajaran IPS Terpadu di SMP N 15 Palu. Geo Tadulako Journal, (3)6.

Borko \& Pittman, M.E. (2008). Video as a tool for fostering productive discussions in mathematics professional development, Teaching and Teacher Education, (24)2, 417-436.

Cheang, Kai I. 2009. Effect of Learner-Centered Teaching on Motivation and Learning Strategies in a Third-Year Pharmacotherapy Course. American Journal of Pharmaceutical Education, 2009; 73(3), 1-8.

Desmita. (2013). Psikologi Perkembangan.Bandung: PT Remaja Rosdakarya.

Hamalik, O. 2012. Kurikulum dan Pembelajaran. Jakarta: Bumi Aksara.

Hidayati, N. (2011). Media Design for Learning Indonesian in Junior High School Level. Social and Behavioral Sciences,(67), 490 - 499

Hunt, S., Wright, A., \& Simonds, C. (2014). Securing the future of communication education: Advancing an advocacy and research agenda for the 21 st century. Communication Education, 63(4), 449-461.

Jarolimek, (1986). Social Studies In Elementary Education. New York: Macmillan Publishing Company.

Kirkorian, H. L., \& Anderson, D. R. (2008). Learning from educational media. In S. L.Calvert, \& B. J. Wilson(Eds.). The handbook of children, media, and development Blackwell: Blackwell Publishing.

Kobre, K.(2012). Video Journalism, Multimedia Story Telling, Combining Audio and Stills, Chapter- 9, Focal Press, Ist Edition.

Kutlu, O. (2009). Factors Affecting The Listening Skill. Social and Behavioral Science, (1) 2013-2022.

Mares, M. -L., Sivakumar, G., \& Stephenson, L. (2015). From meta to micro: Examining theeffectiveness of educational TV. American Behavioral Scientist advance online publicaton.

Martorella, P.H. (1994). Social Studies for Elementary School Children, Developing Young Citizen. New York: Merill.

Morreale, S. P., \& Pearson, J. C. (2008). Why communication education is important: The centrality of the discipline in the 21 st century. Communication Education, 57(2), 224-240.

Moreno,R. \& Mayer,R.E.(2004). Personalized messages that promote science learning in virtual environments, Journal of Educational Psychology, (96)01,165-173.

Nachimuthu,K.(2012). Pressures and Pressures of e-contents in Teaching, International Journal of New Innovations, (01)02, 337-340.

Nawardi, B. Z \& Naga, M. T. (2014). Penerapan Model Cooperative Learning Tipe Rotating Trio Exchange untuk Meningkatkan Aktivitas dan Hasil Belajar Siswa pada Mata Pelajaran IPS Kelas VA SD Negeri 1 Palapa Bandar Lampung Tahun Pelajaran 2012/2013. Diperoleh pada 6 Mei 2018 dari http://digilib.unila.ac.id/630

Oroujulu, N. (2012). The Improtance of Media in Foreign Language Learning. Social and Behavioral Science, (51), 24-28.

Purnamasari, I. (2011). Pengembangan Model Pembelajarana IPS Terpadu Berbasis Lingkungan Sekitar. Jurnal Malih Peddas, (1)1, 12-17.

Sadiman, dkk. (2014). Media Pendidikan Pengertian, Pengembangan, dan Pemanfaatannya. Jakarta: PT Rajagrafindo Persada. 
Sagala, S. 2014. Konsep dan Makna Pembelajaran. Bandung: Alfabeta.

Setiawan, W. (2017). Era Digital dan Tantangannya. Seminar Nasional Pendidikan 2017. Sukabumi

Shah, I \& Khan, M. (2015). Impact of Multimedia-aided Teaching on Students' Academic Achievement and Attitude at Elementary Level. US-China Education Review, 5 (5) : 349-360.

Sobur, A. (2011). Psikologi Umum. Bandung: Pustaka Setia.

Sugiyono. (2015). Metode Penelitian Kuantitaif Kualitatif dan R\&D. Bandung: Alfabeta

Susanto, A. (2016). Teori Belajar \& Pembelajaran di Sekolah Dasar. Jakarta: Prenadamedia Group.

Torres-Ramírez, M., García-Domingo, B., Aguilera, J., \& Casa, d.I (2014). Videosharing educational tool applied to the teaching in renewable energy subjects.Computers \& Education, (73), 160-177.

Trianto. (2011). Model Pembelajaran Terpadu. Jakarta: Bumi Aksara.

Trinova, Z. (2013). Pembelajaran Berbasis Student-Centered Learning pada Materi Pendidikan Agama Islam. Jurnal At-Talim, (20)1, 324-335.

Vansteenkiste, Maarten, et al. 2009. Motivational Profiles From a Self-Determination Perspective: The Quality of Motivation Matters. Journal of Educational Psychology, (101)3, 671-688. 